\title{
Motoneurone pool and the H-reflex
}

\author{
HELENA TÁBOŘ́fKOVÁ AND D. S. SAX \\ From the AMA/ERF Institute for Biomedical Research, Chicago, Illinois, and the Department \\ of Neurology and Psychiatry, Northwestern University Medical School, Chicago, Illinois, U.S.A.
}

Clinical neurology has not yet utilized fully the information that is given by precise investigations of monosynaptic reflexes in man. Tendon jerks provide one of the most common and important clinical tests, but are rarely employed to give precise quantitative information. We can suppose that the excitability of a motoneurone at any instant is some function of the bombardment it has just received by the myriad of excitatory and inhibitory synapses on its surface. In man the preponderant influence is, of course, from higher centres, as can be recognized by the extreme depression of spinal shock. It was an important advance when Hoffmann (1918, 1922) made this monosynaptic reflex test more simple by utilizing electrical stimulation of the popliteal nerve in human subjects in order to evoke the monosynaptic reflex to the gastrocnemius-soleus muscle. Magladery (1955) and Paillard (1955) greatly developed this H-reflex (so named after Hoffmann) technique, and recently there have been many important H-reflex investigations (Coquery, 1962; Mark, 1962; Diamantopoulos and Zander Olsen, 1965; Ioku, Ribera, Cooper, and Matsuoka, 1965; Mayer and Mawdsley, 1965; Stefanis and Matsuoka, 1965; Ishikawa, Ott, Porter, and Stuart, 1966; Matsuoka, Waltz, Terada, Ikeda, and Cooper, 1966).

However, very little consideration has been given to the fraction of the motoneurone pool that is caused to discharge in an H-reflex. Two of the fundamental contributions of Sherrington (1929) to the physiology of the central nervous system were his concepts of motor units and of the motoneurone pool. He coined the term 'motor unit' on the basis of the distribution of the axon of a single motoneurone. Each alpha motor axon is distributed to the muscle fibres of just one muscle and it branches profusely therein to innervate some hundreds of muscle fibres in an exclusive manner (Clark, 1932; Buchthal, Guld, and Rosenfalck, 1957), each muscle fibre usually receiving its motor innervation from just one of the terminals of the branching axon. Thus, the concept of the motor unit implies the

'Present address: Montefiore Hospital \& Medical Center, 111 East 210th Street, Bronx, New York 10467, U.S.A. motor axon with all its branches and the muscleo fibres innervated thereby. The motoneurone pool is을 a related concept and depends upon the finding that the motor unit of any one motoneurone is restricted to some particular muscle. Thus, in the spinal cordow one can envisage that there is a population of alpha. motoneurones which in their totality are responsible for the innervation of some particular muscle, and $\vec{\omega}$ so on for every other muscle. Sherrington, therefore introduced the concept of motoneurone pool top signify this total population of motoneurones belonging to some particular muscle. Experimentally he and his colleagues were able to show that thes reflex responses of muscles were due to the fractio involvement of the total motoneurone pool (Sher rington, 1929).

The monosynaptic reflex response evoked in the cat by a maximal volley in the Group Ia afferent fibres from a synergic group of muscles (the trices sural) has been measured as a fraction of tofaf motoneurone pool of those muscles by Jeffer $\vec{m}$ and Benson (1953) and found to range between 12 . and $26.5 \%$. Apart from a preliminary report last year (Tábớíková, 1966) there has been no measures ment of the activated fraction of the motoneurone pool in the analogous H-reflex. The present invese tigation is a continuation of that work. The fract tional involvement of the motoneurone pool in the H-reflex was determined by measuring the propos? tion of motor units that exhibited refractoriness as consequence of their H-reflex response.

\section{METHOD}

Twenty-six normal young adult volunteers were employed exclusively in this investigation. They lay comfortab in the prone position and the posterior tibial nerve was stimulated monopolarly by an electrode carefully placeg on the skin overlying it in the popliteal fossa ( $c f$. Fig. 1a). The knee was fixed by sand cushions and the stimulating electrode was placed by means of a rigidly mounted Narashige manipulator (Narashige Instrument Tokyo). In this way it was possible to secure and maintaị an optimal location for the stimulating electrode that wess applied on the defatted skin over the posterior tibiad nerve with a mild steady pressure. The effectiveness 354 
this fixation was demonstrated by the constancy of the $M$ response that was evoked by a stimulus submaximal for the motor fibres. These stimuli were square pulses of 1 msec duration and were applied at 5-sec intervals by a Disa Multistim.

The electrical responses were recorded from the soleus muscle by two surface electrodes of standard EEG type that were fixed to the skin by adhesive tape. In this way it was possible to avoid any shift of recording electrodes by muscle movement. Suitable earthed leads minimized artefacts, and the electrical responses were amplified and recorded by a Tektronix 565 scope and Grass camera assemblage. By strobing one of the traces at a very fast speed, it was possible to analyse more precisely the appropriate part of the recorded wave form of the EMG as illustrated in Figures 4 and 5 . In order to make this curve as simple as possible for analysis, special precautions were taken with the placement of the recording electrodes at about $5-\mathrm{cm}$ separation and longitudinally over the midline of the soleus muscle just below the bellies of the gastrocnemii. This location ensures a highly selective leading from the soleus.

\section{RESULTS}

Figure 1b-g shows the sequence of EMGs evoked by progressively stronger stimuli and shows that it is possible to evoke a very large $\mathrm{H}$-response (b) with no trace of the direct motor stimulations that occurred with stronger stimulation in $\mathrm{c}$ to $\mathrm{g}$, there being an accompanying reduction in the $\mathrm{H}$-reflex by antidromic blockage in the manner first described by Hoffmann (1922). This blockage is illustrated in the distance-time plottings of Fig. 2e, f. In Fig. 2e the stimulus is subliminal for the motor fibres as in Fig. 1b, hence there is no antidromic blockage of the H-reflex response (HRV) evoked by the Ia volley (IaV). In Fig. $2 \mathrm{f}$ the stimulus is about half maximum for the motor fibres; hence the antidromic volley (MV) reduces the $\mathrm{H}$-reflex discharge to about half at the collision point (CP).

The interaction of $\mathbf{H}$ and $M$ responses is well illustrated in Fig. $2 \mathrm{~g}$ replotted from a series of observations by Mark (1962), there being a progressively increasing stimulation ( $c f$. Fig. $1 \mathrm{~b}$-g) as shown by the abscissa. The H-reflexes are seen to reach a maximum with a stimulus strength directly exciting very few motor fibres and then decline to zero as the $M$ response increases to maximum.

The four drawings of Fig. 2a-d represent schematically the motoneurone pool of the gastrocnemiussoleus muscle and its activation by progressively increasing stimulus strengths to the popliteal nerve. It is assumed in this diagram that the reflex excitability of the population of motoneurones is not at all correlated with the direct electrical excitability of their motor axons in the popliteal fossa. This is illustrated diagrammatically by representing the fraction discharging in the H-reflex by a sector of the motoneurone pool, while the motoneurones belonging to the motor axons directly excited are represented by the circular dotted zones. It should be noted that, contrary to the postulated non-correlation, Henneman, Somjen, and Carpenter (1965) found that in cats the triceps surae motoneurones of lowest threshold usually had thinner axons than those of higher threshold and hence would be expected to be less excitable by electric stimulation. However, the observed correlation in the cat ventral root fibres was only partial, and so provisionally may be neglected in our present consideration of human motor axons in the popliteal fossa.

Figure 2a illustrates the H-reflex evoked by a submaximum Group Ia volley, there being no direct excitation of motor fibres as shown diagrammatically in $\mathrm{e}$. In $\mathrm{b}$ the stimulus excites very few motor axons (cf. Fig. 1c), but is maximum for the Ia fibres and so gives the full expansion of the sector; $c$ and $d$ show further increases of stimulus strength with progressive growth of the dotted zone and the consequent restriction of the zone (horizontally hatched) giving the H-reflex because of the collision in the motor pathway as indicated in Figure $2 \mathrm{f}$.

Presumptive evidence for activation of a large fraction of the motoneurone pool has been obtained in several subjects in which the responses to graded intensities of stimulation gave a series such as that illustrated in Figure 1b-g. As shown in Fig. 1g the strongest stimulation caused the blockade of the H-reflex to be virtually complete. The M-spike response produced in these circumstances can therefore be assumed to be due to activation of almost $100 \%$ of the motor axons of the gastrocnemiussoleus muscle, and hence of the motor units of this muscle. The largest action potential of the H-reflex in Fig. 1c is a little smaller in size than the maximum M-spike of $\mathbf{g}$. However, close inspection reveals that the triphasic H-reflex potential is composed of a more asynchronous response of the motor units, the interval between the initial and terminal positive waves being $6 \mathrm{msec}$ as compared with $5 \mathrm{msec}$ for the M-spike. This asynchronism can, of course, be attributed to the much longer neural conduction pathway for the H-reflex with the interpolation of a synaptic relay. It seems likely that the increased asynchronism of the constituent motor unit responses is sufficient to account for the smaller size of the H-reflex spike relative to the M-spike in Figure 1g. Similar evidence for a virtually total activation of the motoneuronal pool has been obtained in several other subjects.

Figure 3 illustrates diagrammatically the arrangement for measuring the proportion of the motoneurone pool activated in the $\mathrm{H}$-reflex response evoked by a Group Ia volley. The $S_{1}$ stimulus excites 


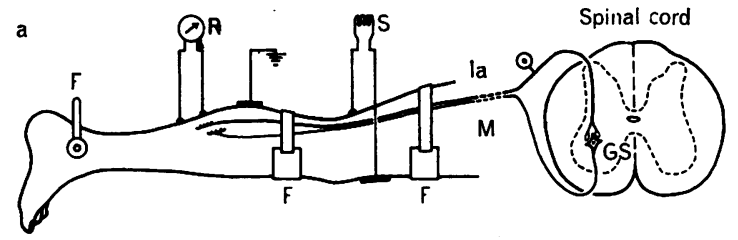

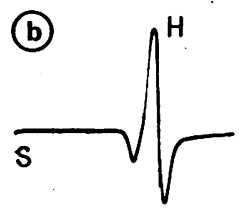
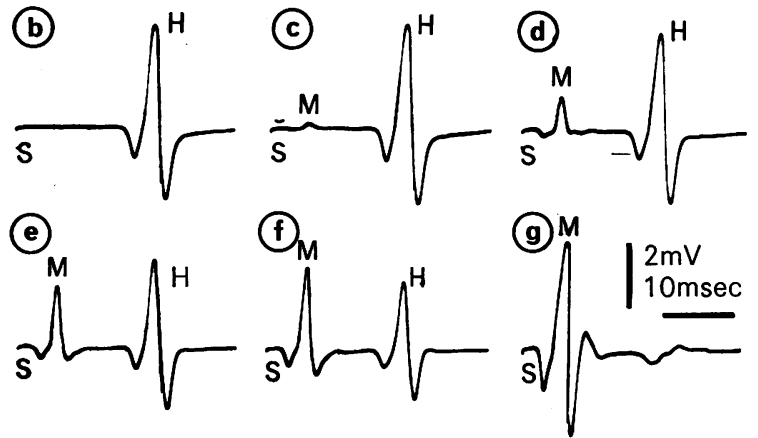

FIG. 1. H-reflex pathways, technique and specimenz records in human subject. Stimulation is applied unifocally by $S$ to the posterior tibial nerve in the popliteal $\overrightarrow{\overline{\mid}}$ fossa, and the reflex pathway runs up to the spinal cord by Ia fibres and out to the gastrocnemius-soleus muscle by motor fibres, $M ; b-g$ show responses to progressively stronger stimuli as described in the text.

FIG. 2. Diagrammatic illustration of the interaction of the $M$ and $H$ responses. In a-d the outer circle represents $\omega_{-}$ the total motoneurone pool, the sector is the pool activated in the H-reflex, and the inner circle in b-d the motor axozs. directly excited to give the $M$ response. The pathways for the $H$ and $M$ responses are shown in the distance-time plotio

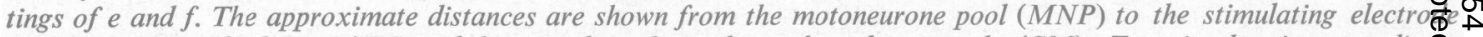
on the posterior tibial nerve (TN) and the recording electrode on the soleus muscle (SM). Zero in the time coordin $\$$ (abscissae) gives the time of the stimulus (S) to TN. In e the weaker S sets up only a Ia volley (IaV), that evokes $\mathbb{\mathbb { Q }}_{\mathbf{e}}$ $H$-reflex volley (HRV). In $f$ the stronger $S$ directly excites the motor axons setting up a motor volley (MV) propagatio in both directions, but more slowly than the IaV, and colliding at CP with HVR, which is thereby reduced is

SUBMAX $1 \mathrm{a}$

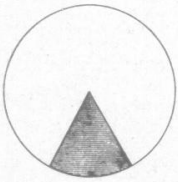

AX 1a

small $M$

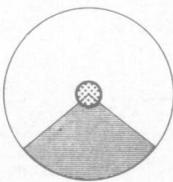

$\mathrm{H}$ responses

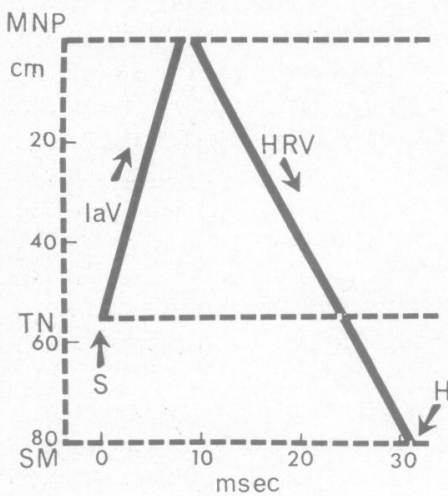

e d

MAX 1a large $M$ almost MAX M
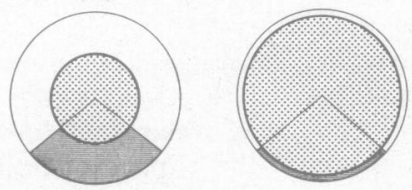

$M$ responses

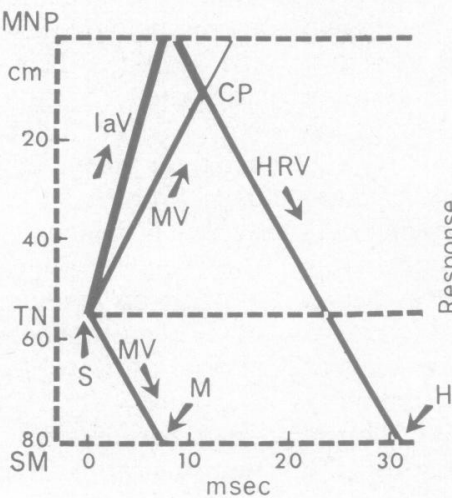
its further course peripherally, as is indicas by the truncated hatched sectors in $b$ to It is to be noted that from $S$ the IaV wo also propagate peripherally but this may neglected in the present treatment. In $g$ the sizes of the $H$ and $M$ responses are plotted as ordinates from a series similar to that of Fig. I b-g, the stimulus strengths in $m A \overline{\bar{O}}$ being abscissae. Points replotted from a fig- ָै ure of Mark's (1962).

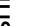


a small $M$ response $\left(M_{1}\right)$ and a virtually maximum Ia afferent volley (IaV) that monosynaptically evokes the discharge from the motoneurone pool so giving the $\mathrm{H}$-reflex response $\left(\mathrm{H}_{1}\right)$. It is seen that this reflex discharge (HRV) is only negligibly reduced at the collision point (CP) by the minimal antidromic volley (MV), in the motor axons. The $S_{2}$ stimulus is much stronger so that it excites directly a large proportion of the motor axons (note the large MV and large $M$ ) with the consequence that at the CP the H-reflex discharge is largely blocked by collision as already described in Fig. $2 \mathrm{f}$, there being as a consequence only a small $\mathrm{H}_{2}$. Since it is assumed that there is no correlation between the direct excitability of the motor fibres and the reflex excitability of the motoneurones, it is possible to determine the fraction of the motoneurone pool activated by the $\mathrm{H}_{1}$ response. When, as shown by the arrow, the $S_{2}$ stimulus is advanced closer to the time at which the H-reflex is passing the stimulated point, it will find more and more motor axons and their muscle fibres refractory. Evidently, when the $S_{2}$ stimulus is so early that all muscle fibres responding to the $\mathrm{H}_{\mathbf{1}}$-reflex are refractory to $S_{2}$, the fractional reduction of the $M_{2}$ response gives a measure of the fraction of the motoneurone pool responding in the $\mathrm{H}_{1}$ reflex.

Figure 4a shows specimen records of this interaction technique for measuring the fraction of the motoneurone pool activated in the $\mathrm{H}_{1}$ reflex which is shown in the first control record. The second control record shows the large $M_{2}$ response to $S_{2}$ with a small subsequent $\mathbf{H}_{2}$. In both cases the upper traces give the full control responses, while the lower are expanded traces of the segment used for determining overlap in the $S_{1} S_{2}$ responses. In the series of specimen records to $S_{1} S_{2}$ stimuli it can be seen that the $M_{2}$ response is large at the longest $S_{1} S_{2}$ interval (lowest tracing to right) and is reduced progressively as $S_{2}$ is moved earlier relative to $S_{1}$. The sizes of $M_{2}$ in each of these positions can be measured by the subtraction technique, and to facilitate this there is at each testing interval superposition of the combined $S_{1} S_{2}$ response on the control $H_{1}$ response to $S_{1}$ alone. The plotted measurements from such a series of records can be calculated as percentages of the $\mathbf{M}_{2}$ response and are plotted in $\mathbf{B}$ as ordinates against stimulus intervals as abscissae. The plotted curve shows that at the point of maximum effectiveness the $H_{1}$ reflex reduced $M_{2}$ by $37 \%$ and hence is shown to activate $37 \%$ of the motoneurone pool. Figure 5 illustrates a similar investigation in another experiment where the percentage of activation was $78 \%$.

It was a regular feature that the maximum reduction of the $\mathbf{M}_{2}$ response occurred at intervals from
0 to $1 \mathrm{msec}$ on the abscissal scaling. Zero on this scale was chosen so that the negative summits of $H_{1}$ and $M_{2}$ would be superimposed. At negative intervals the $\mathbf{M}_{2}$ response actually leads $H_{1}$, so the subtraction ceases to have meaning. At the longer positive intervals the recovery from refractoriness is seen to be well advanced at 3 to $4 \mathrm{msec}$.

As a rule $\mathrm{H}$-reflexes excited by a stimulus virtually maximum for Ia fibres gave an H-reflex from about half of the motoneurone pool. However, in several subjects there has been virtually $100 \%$ activation, as may be seen in Figure 6 . At the longest testing interval the $M$ response was virtually as large as the control and it was not appreciably reduced until it was superimposed on the latter part of the H-reflex. Further advance of the $S_{2}$ stimulus then resulted in a rapid decrease of $M_{2}$, and in the last two records of the series the spike induced by the $S_{1} S_{2}$ stimulation could be exactly superimposed on the control $\mathrm{H}_{1}$ reflex response. Thus it was established that, within the limits of accuracy of this experiment, the $\mathrm{H}$ reflex was occurring in $100 \%$ of the motoneurone pool. It will be noted that in the lowest series of frames there was a progressive increase in the $\mathrm{H}$-response $\left(\mathrm{H}_{2}\right)$ evoked by the second stimulus. This is, of course, to be expected as refractoriness prevents the second stimulus from exciting the motor axons and so blockading the $\mathbf{H}_{2}$-reflex as already described and illustrated in Figure $2 f$.

It may seem surprising that the $\mathrm{H}_{2}$ response was not fully recovered under such conditions. There are two explanations of this incomplete recovery. Firstly, there is the depression of a second monosynaptic reflex evoked by the same synapses (Eccles and Rall, 1951), an effect called homosynaptic depression and attributable to transmitter depletion.

Secondly, a contributory explanation can be developed by considering more precisely the actual mechanism involved in the reduction of $\mathbf{M}_{2}$ by the refractoriness arising from the $\mathrm{H}_{\mathbf{1}}$-reflex. There is considerable asynchronism of the $\mathrm{H}$-reflex because of its long conduction path and the central synapse thereon. For this reason it is probable that all the motor fibres activated in the H-reflex are not refractory at any one instant. However, this contingency does not tell against the reliability of the technique because the observations concern the responses of the muscle fibres and not the motor axons. It has been shown that with mammalian muscle the refractoriness under these conditions is increased by more than $1 \mathrm{msec}$ (Eccles and O'Connor, 1939). Thus in the last two records of Fig. 6 many of the motor axons probably were excited by $S_{2}$ and hence would contribute to the considerable reduction of $\mathrm{H}_{2}$; yet there was complete refractoriness as tested by the muscle action potentials. 


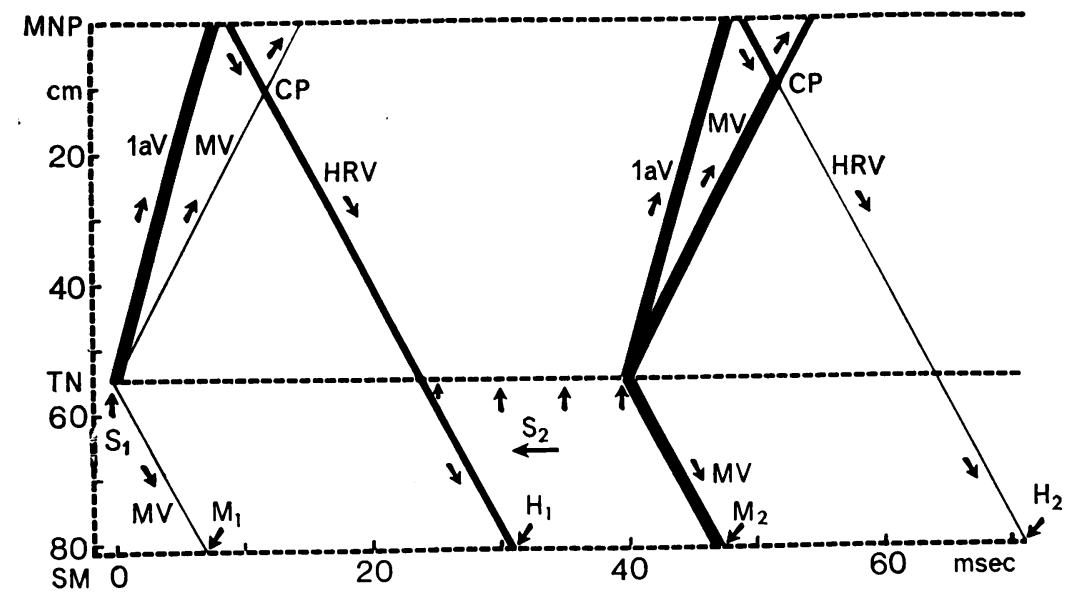

FIG. 3. Distance-time diagram showing $M$ and $H$ responses evoked by weak $S_{1}$ and strong $\mathrm{S}_{2}$ stimuli. Diagrammatic plotting resembling that of Fig. 2 e, $f$, but $S_{1}$ evokes a small $M V$ and $M$ response, and $S_{2}$ a large $M V$ with consequent blocking of almost all $H R V$ at the collision point, $C P$, so that $M_{2}$ will be large and $\mathrm{H}_{2}$ very small. As shown by the horizontal arrow, as $S_{2}$ is moved earlier, there will be eventually $a$ reduction of the $M_{2}$ response in all those motor units responding to $S_{1}$ by the $H R V$.
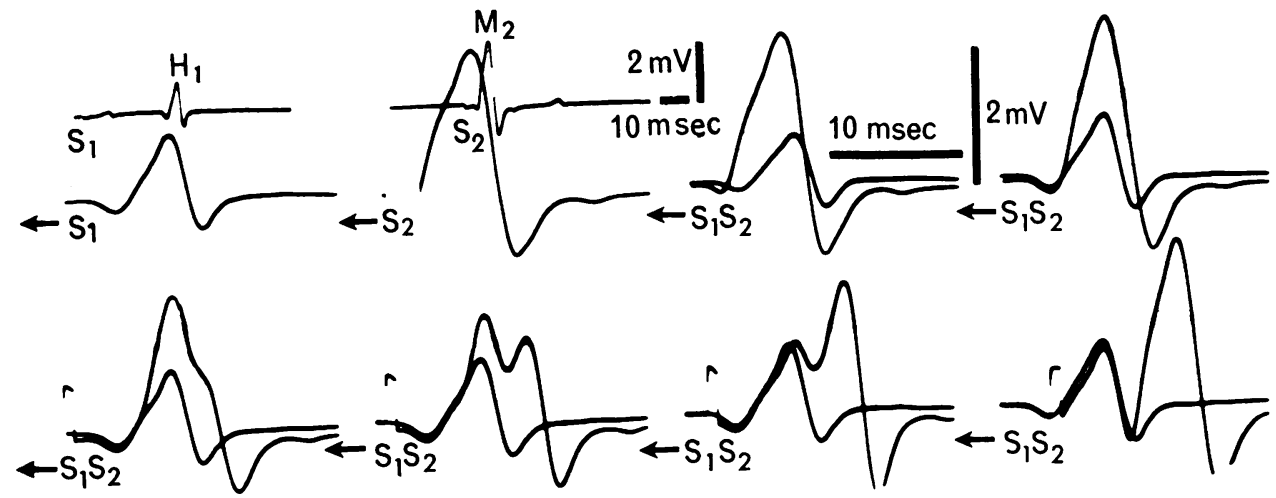

a

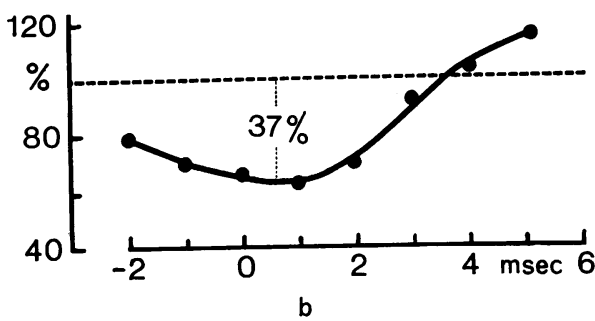

FIG. 4. Fraction of motoneurone pool engaged in $H$ reflex response. In a the first frame is the $H_{1}$ response to $S_{1}$, and the second frame the $M_{2}$ response to $S_{2}$. The upper traces show the responses on a slow sweep, the lowe traces being at higher amplification and much faster sweep speed as shown in the calibration scales. In tho subsequent six frames of a only the fast sweeps are shown there being a progressive delay of $S_{2}$ relative to $S_{1}$, and each frame there is super-position of the combined $S_{1} S_{\text {- }}$. response on the $H_{1}$ response to $S_{1}$ alone. Thus, subtractio想 gives the size of the $M_{2}$ response not blocked by refractorit ness, and this size is plotted in $b$ as a percentage of the control $M_{2}$ response with as abscissae the $S_{1}-S_{2}$ intervatik zero being arbitrarily set as the interval at which the negative spike potentials of $H_{1}$ and $M_{2}$ are simultaneous. 

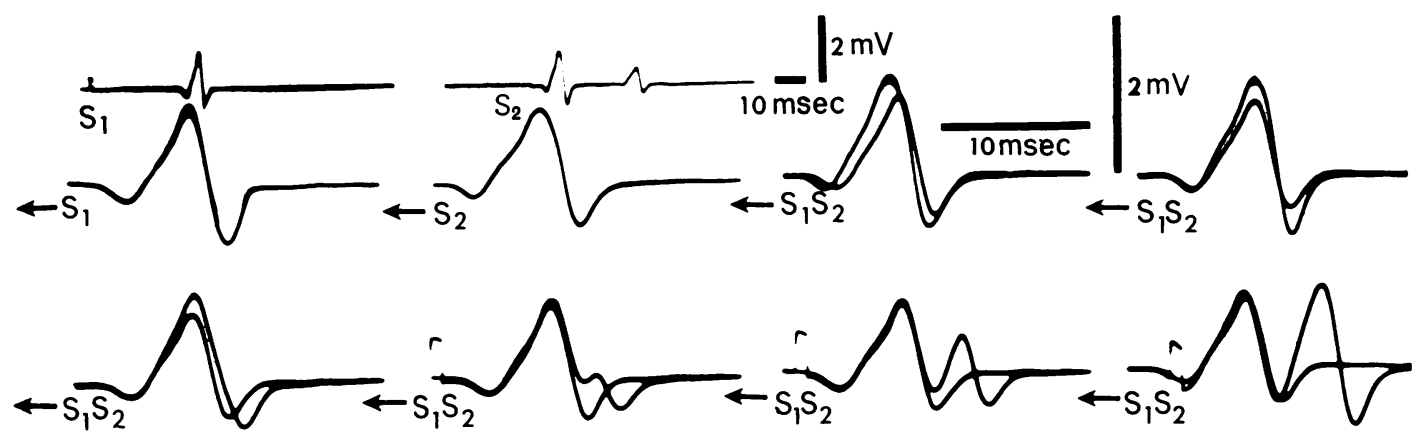

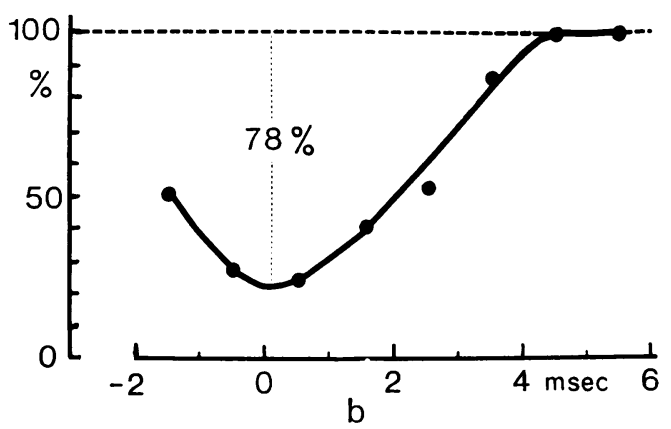

a

FIG. 5. Fraction of motoneurone pool engaged in the $H$ reflex response. Series of records as in Fig. 4, but from another experiment in which the $H$-reflex occurred in a much larger fraction of the pool, as shown by the large reduction of the $M_{2}$ response.<smiles>[M]C(CS)CC(C)C</smiles>

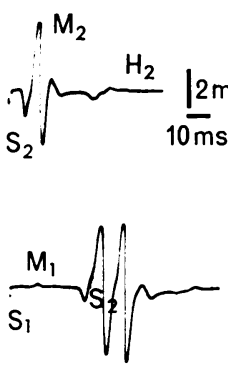

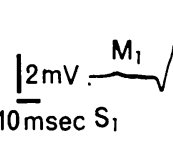

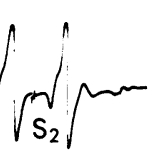

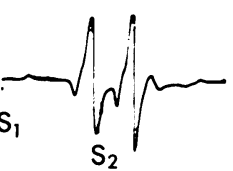<smiles>CCC1CCCCC1CC</smiles><smiles>CCCCCC(C)N(C)S</smiles><smiles>CCCC(C)S</smiles><smiles>[M]C(CS)SCCCCC</smiles><smiles>CC1CC(C)C(C)(CS)C1</smiles>

FIG. 6. $H_{1}-M_{2}$ series with complete occlusion of $\mathrm{M}_{2}$ by $\mathrm{H}_{1}$. The first two frames give the control $\mathrm{H}_{1}$ and $\mathrm{M}_{2}$ responses as in Figure 4. In the subsequent frames the $S_{1} S_{2}$ interval was progressively shortened so that there was superposition of the negative spike potentials of $H_{1}$ and $M_{2}$ in the two last frames. Further description in text.

Figure 7 illustrates the curves obtained from the most extreme experiments: a shows the smallest fraction that we have determined $(24 \%)$, while in $b$ the H-reflex involved $100 \%$ of the motoneuronal pool.

\section{DISCUSSION}

It must be recognized that the measurements here reported for the motoneuronal pool involvement in the H-reflex apply strictly only to the soleus muscle, 


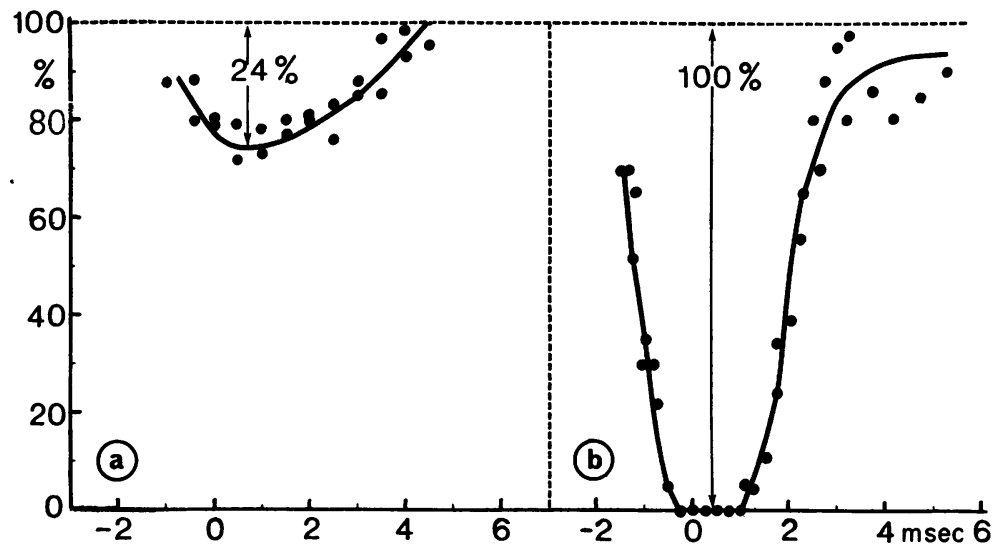

FIG. 7. Fractions of the motoneurone engaged in the $H$-reflex response. In $a$ and $b$ there are plottings as in Figs. $4 b$ and $5 b$, for the smallest and largest fractional involvements of the motoneurone pool by the H-reflex.

tically this calculation can be done if the following conditions hold: non-correlation between $\mathrm{H}$-reflex excitability of motoneurones and the electrical excitability of their axons; a good threshold separation between the Ia and the motor fibres, so that it is possible to evoke a maximum Ia volley by a stimulus only giving a weak $\mathbf{M}$ response; similar temporal dispersions of the motor unit responses in the $\mathbf{M}$ and $H$ action potentials; restriction of the $M$ response to the motor units of the muscle under examination (gastrocnemius-soleus).

The basis of the calculation may be illustrated by reference to Figures $2 b$ and $d$. If $x$ is the fraction of the motoneurone pool discharging in the H-reflex evoked by a maximum Ia volley, then for the $S_{1}$ stimulus in b the size of the H-reflex $\left(\mathrm{H}_{1}\right)$ is reduced by the small collision in the motor fibres responding directly $\left(M_{1}\right)$, which will be $x M_{1}$, that is, the small sector of the dots in $b$. Hence the total size of the motoneurone pool is given by $\left(H_{1}+M_{1} x\right) / x$. Similarly in Fig. 2d the much larger direct response $\left(M_{2}\right)$ to the strong stimulus $\left(S_{2}\right)$ greatly reduces by collision the $\mathrm{H}$ response to $\mathrm{H}_{2}$, and again the total size of the motoneurone pool is given by $\left(\mathrm{H}_{2}+\mathrm{M}_{2} \mathrm{x}\right) / \mathrm{x}$. Hence,

$$
\begin{gathered}
\left(H_{2}+M_{2} x\right) / x=\left(H_{1}+M_{1} x\right) / x, \text { and } \\
x=\left(H_{1}-H_{2}\right) /\left(M_{2}-M_{1}\right) .
\end{gathered}
$$

Table I shows that the calculated proportion of the motoneurone pool activated by the H-reflex is always less than that experimentally observed, and sometimes there is a very serious discrepancy. Evidently the four initial assumptions have led to this error. The most probable explanation is that the $S_{1}$ stimulus was too weak to excite a maximum Ia volley. It will be noted that the discrepancy tended to be less in those subjects where H-refiexes were large. It can be concluded that measurement of the H-reflex involvement of the motoneurone pool
T A B LE I

CALCUlated AND EXPERIMENTAL VALUES FOR PERCENTAGES OF MOTONEURONAL POOL (MNP) RESPONDING IN

\begin{tabular}{|c|c|c|c|c|c|c|}
\hline \multirow{2}{*}{ Subject } & $M_{1}$ & $\mathrm{H}_{1}$ & $M$, & $\mathrm{H}_{2}$ & $\begin{array}{l}\% \text { calculated } \\
\quad 100\left(H_{1}-H_{2}\right)\end{array}$ & Experimenta \\
\hline & \multicolumn{4}{|c|}{$m V$} & $M_{2}-M_{1}$ & \\
\hline D.S & 0.2 & 0.95 & 2.90 & 0.80 & 6 & 52 \\
\hline H.T. & 0 & $1 \cdot 1$ & $1 \cdot 1$ & 0.6 & 45 & 78 \\
\hline H.T. & $1 \cdot 1$ & $1 \cdot 15$ & $2 \cdot 70$ & 0.35 & 30 & 37 \\
\hline D.S. & 0.05 & 1.0 & $2 \cdot 6$ & 0.6 & 16 & 39 \\
\hline M.N. & 0 & $2 \cdot 4$ & $2 \cdot 4$ & 1.9 & 21 & 63 \\
\hline B.P. & $0 \cdot 15$ & $1 \cdot 3$ & 2.85 & 0.55 & 28 & 50 \\
\hline S.K. & 0.15 & $1 \cdot 1$ & $1 \cdot 1$ & 0.55 & 58 & 68 \\
\hline B.W. & 0 & $2 \cdot 15$ & 3.5 & 1.65 & 14 & 54 \\
\hline H.S. & 0 & 0.8 & $2 \cdot 7$ & 0.75 & 2 & 24 \\
\hline S.H. & 0 & 1.0 & 1.05 & 0.6 & 38 & 82 \\
\hline P.I. & 0 & 1.6 & $4 \cdot 4$ & 0.85 & 17 & 19 \\
\hline B.H. & 0.3 & $4 \cdot 1$ & 4.00 & 0.9 & 87 & 100 \\
\hline C.B. & 0 & 1.05 & 2.45 & 0.8 & 10 & 45 \\
\hline L.P. & & 0.7 & $2 \cdot 2$ & 1.05 & 16 & 27 \\
\hline L.P. & $0 \cdot 15$ & $1 \cdot 5$ & $2 \cdot 35$ & $1 \cdot 15$ & 16 & 41 \\
\hline
\end{tabular}
H-REFLEXES

should be experimentally determined as described above, rather than calculated.

Table I shows the $\mathrm{H}$ reflexes for 12 separate subjects, there being recordings from three subjects on separate experimental days. The differences in percentages observed in these subjects can be attributed to the 'state of alertness' of the subject. With the onset of drowsiness the H-reflex could be greatly depressed. Such series were, of course, rejected.

The measurement of the motoneuronal fraction involved in H-reflexes should be a standard procedure in all investigations in $\mathbf{H}$-reflexes. For example, in testing the effect of muscle stretch on the H-reflex it was sometimes found that there was almost no change in sizes of the reflexes (Táboříková, N Provini, and Decandia, 1966), and in $\mathrm{H}_{1} \mathrm{H}_{2}$ inves- $N$ tigations (Sax and Táboříková, unpublished observations), there may be no sign of facilitation because 
$\mathrm{H}_{2}$ excites virtually $100 \%$ of the pool. This stability of the $\mathrm{H}$-reflex under conditions of presumed inhibitory or facilitatory influences would be expected if motoneurones were so powerfully excited that all of them were supramaximally excited in the H-reflex.

\section{SUMMARY}

H-reflexes have been evoked in the conventional manner by maximal stimulation of the Group Ia afferent fibres in the popliteal fossa of normal young adults. The fractions of the motoneuronal pool responding in these reflexes have been measured by a refractoriness technique. The measured fraction could be as small as $24 \%$, but usually was about $50 \%$, though in three subjects it was virtually $100 \%$. An attempt was made to calculate the fraction from measurements of the $M$ and $H$ responses evoked by weak and strong stimuli, the former evoking weak $\mathbf{M}$ and large $\mathbf{H}$ responses, the latter large $\mathbf{M}$ and small $H$ responses. This method gave lower values than the refractoriness technique, there being often a grave discrepancy. It is suggested that the refractoriness technique should be employed as a routine testing procedure in $\mathrm{H}$-reflex investigations.

We wish to thank Professor Sir John Eccles for his very helpful criticism and advice.

\section{REFERENCES}

Buchthal, F., Guld, C., and Rosenfalck, P. (1957). Multielectrode study of the territory of a motor unit. Acta physiol. scand., 39, 83-104.

Clark, D. A. (1932). Muscle counts of motor units: a study in innervation ratios. Amer. J. Physiol., 96, 296-304.

Coquery, J.-M. (1962). Les variations 'spontaneés' du réflexe de Hoffmann. (These de Doctorat en Neurophysiologie, October, 1962.) Université D'Aix-Marseille, Faculté des Sciences de Marseille.

Diamantopoulos, E., and Zander Olsen, P. (1965). Motoneuron excitability in normals and patients with abnormal muscle tone, in Sixth International Congress of Electroencephalography and Clinical Neurophysiology, p. 119. Vienna Academy of Medicine, Vienna.

Eccles, J. C., Eccles, R. M., and Lundberg, A. (1957). The convergence of monosynaptic excitatory afferents on to many different species of alpha motoneurones. J. Physiol. (Lond.), 137, 22-50.

- , and O'Connor, W. J. (1939). Responses which nerve impulses evoke in mammalian striated muscles. Ibid., 97, 44-102.

-, and Rall, W. (1951). Effects induced in a monosynaptic reflex path by its activation. $J$. Neurophysiol., 14, 353-376.

Henneman, E., Somjen, G., and Carpenter, D. O. (1965). Functional significance of cell size in spinal motoneurons. Ibid., 28, 560580.

Hoffmann, P. (1918). Über die Beziehungen der Sehnenreflexe zur willkürlichen Bewegung und zum Tonus. $Z$. Biol., 68, 351.

- (1922). Untersuchungen über die Eigenreflexe (Sehnenreflexe) Menschlichen Muskeln. Jul. Springer Verlag, Berlin.

Ioku, M., Ribera, V. A., Cooper, I. S., and Matsuoka, S. (1965). Parkinsonism: electromyographic studies of monosynaptic reflex. Science, 150, 1472-1475.

Ishikawa, K., Ott, K., Porter, R. W., and Stuart, D. (1966). Low frequency depression of the $H$ wave in normal and spinal man. Exp. Neurol., 15, 140-156.

Jefferson, A., and Benson, A. (1953). Some effects of post-tetanic potentiation of monosynaptic response of spinal cord of cat. J. Neurophysiol., 16, 381-396.

Magladery, J. W. (1955). Some observations on spinal reflexes in man. Pfügers Arch. ges. Physiol., 261, 302-321.

Mark, R. (1962). Analyse électrophysiologique des réflexes d'étirement du muscle triceps sural chez l'homme. (These de Doctorat en Neurophysiologie.) Université D'Aix-Marseille Faculté des Sciences de Marseille.

Matsuoka, S., Waltz, J. M., Terada, C., Ikeda, T., and Cooper, I. S. (1966). A computer technique for evaluation of recovery cycle of the H-reflex in the abnormal movement disorders. Electroenceph. clin. Neurophysiol., 21, 496-500.

Mayer, R. I., and Mawdsley, C. (1965). Studies in man and cat of the significance of the $\mathbf{H}$ wave. J. Neurol. Neurosurg. Psychiat., 28, 201-211.

Paillard, J. (1955). Réflexes et régulations d'origine proprioceptive chez l'homme. Librairie Arnette, Paris.

Sherrington, C. S. (1929). Some functional problems attaching to convergence. Ferrier Lecture, Proc. Roy. Soc. B, 105, 332-362.

Stefanis, C. N., and Matsuoka, S. (1965). Spinal motoneurone hyperexcitability in patients with Parkinson's disease, as revealed by the recovery curve of the H-reflex, in Sixth International Congress of Electroencephalography and Clinical Neurophysiology, p. 119. Vienna Academy of Medicine, Vienna.

Tábořiková, H. (1966). Fraction of the motoneurone pool activated in the monosynaptic $\mathrm{H}$-reflexes in man. Nature (Lond.), 209, 206-207.

- Provini, L., and Decandia, M. (1966). Evidence that muscle stretch evokes long-loop reflexes from higher centres. Brain Res., 2, 192-194. 